Working Paper No. 652, 2005

\title{
The Todaro Paradox Revisited
}

by Yves Zenou

IUI, The Research Institute of Industrial Economics

P.O. Box 55665

SE-102 15 Stockholm

Sweden 


\title{
The Todaro Paradox Revisited
}

\author{
Yves Zenou* \\ IUI, GAINS and CEPR
}

November 9, 2005

\begin{abstract}
The Todaro Paradox states that policies aimed at reducing urban unemployment are bound to backfire: they will raise rather than reduce urban unemployment. The aim of this paper is to reexamine this paradox in the context of efficiency wage and search-matching models. For that, we study a policy that consists in decreasing the urban unemployment benefit. In an efficiency wage model, we find that there is no Todaro paradox while this is not always true in a search-matching model since a decrease in the urban unemployment benefit can increase both urban employment and unemployment.
\end{abstract}

Key words: Efficiency wages, search-matching, rural-urban migration, policy.

JEL Classification: D83, J41, J64, O15.

*IUI, The Research Institute of Industrial Economics, Box 55665, 10215 Stockholm, Sweden. E-mail: yvesz@iui.se 


\section{Introduction}

In two seminal papers, Todaro (1969) and Harris and Todaro (1970) have developed a canonical model of rural-urban migration. The main idea is quite simple since it says that migration will occurs as long as the urban expected income (i.e. income times the probability to find an urban job) is higher than the rural one. These papers have been so influential that they are referred in the literature to as the Harris-Todaro model. One of the main issues raised in these papers was that creating urban jobs may increase rather than decrease urban unemployment because of the induced negative effect on rural migration, which may outweight the positive effect of creating jobs (Todaro, 1976). This is referred to as the Todaro paradox.

Researchers have tried to investigate further this seemingly counterintuitive result. There is a long line of papers, including Zarembka (1970), Blomqvist (1978), Arellano (1981), Takagi (1981), Nakagome (1989), Brueckner (1990), Stark et al. (1991), Raimondos (1993), Brueckner and Zenou (1999), Brueckner and Kim (2001). Most of these papers give conditions under which the Todaro paradox exists. In the recent literature, a new force has been added by explicitly introducing the land market in a Harris-Todaro model (Nakagome, 1989, Brueckner, 1990, Brueckner and Zenou, 1999, Brueckner and Kim, 2001). In that case, the urban-land-rent escalation provides an additional force that limits migration and the Todaro paradox does not in general exist.

In this literature, a Todaro paradox exists if an increase in urban employment (endogenous variable) leads to an increase in urban employment (endogenous variable). Because it is always delicate to analyze the impact of an endogenous variable on another, we consider here the effect of a decrease of urban unemployment benefit on urban unemployment. Indeed, in our model, we assume that an unemployment benefit is paid to the urban sector. In the context of a third world country it may interpreted as family or institutional support in the urban sector. A country like China for example has important social benefit policies. The state-sponsored social insurance system, which accounts for the bulk of public social spending, is now being gradually improved and extended to cover all urban workers (see e.g. Knight and Song, 2005). ${ }^{1}$ In our framework, a Todaro paradox will exist if a reduction in the urban

\footnotetext{
${ }^{1}$ All our analysis would be unchanged if we interpret unemployment as the informal sector (like for example in Brueckner and Zenou, 1999). In that case, the unemployment benefit would mean the revenue of informal workers and thus an unemployment benefit policy would take the form of an increase in the revenue of the urban informal sector.
} 
unemployment benefit (exogenous variable and policy instrument) leads to an increase of both urban employment and unemployment. This is a paradox since a reduction in the unemployment benefit has the natural effect to increase urban employment but the counterintuitive effect to also increase urban unemployment.

In order to analyze this policy, we use two standard models of the labor market that have both strong empirical supports ${ }^{2}$ and that have been used in the rural-urban migration literature. An efficiency wage model (see Stiglitz, 1974, 1976, Moene, 1988, Smith and Zenou, 1995, Brueckner and Zenou, 1999, Brueckner and Kim, 2001, for its utilization in the context of rural-urban migration) is first developed. We then consider a search-matching model. There is a tradition of search models in the migration literature. The early models were using the old search approach where only one side of the market (the workers) was modeled (see e.g. Fields, 1975, 1989, Banerjee, 1984, Mohtadi, 1989, etc.). There is also a more recent literature, which incorporates the search-matching approach a la Pissarides-Mortensen (Mortensen and Pissarides, 1999; Pissarides, 2000) in a Harris-Todaro model (see Coulson et al., 2001, Ortega, 2000, Sato, 2004, Laing et al., 2005). This is what we are using here.

In an "autarky" model where only the urban sector is considered and no rural-urban migration takes place, then in either an efficiency wage or a search matching model, a decrease in the unemployment benefit always reduces urban unemployment and increases urban employment. When free mobility between rural and urban areas is allowed, the results are not anymore straightforward. We find that in an efficiency wage model a la Shapiro and Stiglitz (1984), there is no Todaro paradox. The intuition is as follows. When the government decreases the unemployment benefit, this has a direct negative effect on urban wages and thus more urban jobs are created. This is the attraction force to the city. This implies that rural wages increase but since there are more jobs in cities and efficiency wages act as a worker's discipline device, urban firms reduce their wages because it becomes more difficult to find a job. Because the

\footnotetext{
${ }^{2}$ The traditional attempts to test efficiency wage theory showed that there are large wage differences between sectors for identical workers, due to differences in supervision/monitoring rates (Kruger and Summers, 1988; Dickens and Katz, 1987; Murphy and Topel, 1990; Neal, 1993). So identical individuals working in different sectors can experience different unemploment rates because of inter-industry wage differences. Concerning the search-matching model, the empirical supports are also very strong. See in particular Devine and Kiefer (1991) and Pissarides and Petrongolo (2001).
} 
repulsion force is strong enough, the net effect is that creating urban jobs via a reduction in unemployment benefit reduces urban unemployment because of the discouraging effect of efficiency wages on migration.

In the case of a search-matching model where wages are bargained, a Todaro paradox may exist if a condition on parameters is satisfied. Indeed, a decrease in the unemployment benefit has a direct negative effect on bargained wages. As a result, because it is cheaper and thus more profitable to hire a worker, more firms enter the urban labor market and more jobs are created, and thus rural-urban migration increases. However, when the unemployment benefit decreases, there is a also direct negative effect on migration since urban wages are lower and thus less rural workers migrate. The net effect is thus ambiguous. A condition that guarantees that the indirect positive effect on migration is larger than the direct negative effect leads to a Todaro paradox since a decrease in unemployment benefit increases in this case both urban employment and unemployment.

\section{Urban efficiency wages}

There are two regions: Rural and urban. It is assumed that the rural wage is flexible enough to guarantee that there is no rural unemployment; this wage is denoted by $w_{L}^{R}$. There is a continuum of ex ante identical workers whose mass is $N$. Among the $N$ workers, $N^{C}$ and $N^{R}$ live respectively in cities and rural areas, i.e. $N=N^{C}+N^{R}$, and

$$
\begin{gathered}
N^{C}=L^{C}+U^{C} \\
N^{R}=L^{R}
\end{gathered}
$$

where $L^{g}$ and $U^{g}$ are respectively the total employment and unemployment levels in region $g=C, R$ ( $C$ for cities and $R$ for rural areas). As stated above, there is no unemployment in rural areas. Thus, by combining these two equations, we obtain:

$$
U^{C}=N-L^{C}-L^{R}
$$

The unemployment rate is then given by:

$$
u^{C}=\frac{U^{C}}{U^{C}+L^{C}}=\frac{N-L^{C}-L^{R}}{N-L^{R}}
$$

Both regions produce the same good but use different techniques. In region $g, y^{g}$ units of output are produced and $L^{g}$ workers are employed. This is a 
short-run model where capital is fixed and the production function in region $g=C, R$ is given by

$$
y^{g}=F^{g}\left(L^{g}\right) \quad, F^{\prime g}\left(L^{g}\right)>0 \text { and } F^{\prime \prime g}\left(L^{g}\right) \leq 0
$$

We also assume that the Inada conditions hold, that is $\lim _{L^{g} \rightarrow 0} F^{g^{\prime}}\left(L^{g}\right)=+\infty$ and $\lim _{L^{g} \rightarrow+\infty} F^{g \prime}\left(L^{g}\right)=0$. The price of the good is taken as a numeraire and, without loss of generality, normalized to 1 . We use the standard efficiency wage model, as proposed by Shapiro and Stiglitz (1984). Each individual supplies one unit of labor. As in the standard efficiency wage model, there are only two possible levels of effort: either the worker shirks, exerting zero effort, $e=0$, and contributing zero to production, or he/she does not shirk, providing full effort.

The model is dynamic and we assume that, if rural workers want to get an urban job, they have first to move to the city, be unemployed and gather information about jobs, and then can eventually obtain an urban job. In the urban labor market, firms cannot perfectly monitor workers so that there is a probability of being detected shirking, denoted by $\theta$. If a worker is caught shirking, he/she is automatically fired. Time is continuous and workers live forever. We assume that changes in employment status are governed by a Poisson process in which $a$ is the (endogenous) job acquisition rate and $\delta$ the (exogenous) destruction rate. Let us denote by $r$ the common discount rate of all workers. Then, the standard steady-state Bellman equations for the non-shirkers, the shirkers and the unemployed are given by:

$$
\begin{gathered}
r I_{L}^{N S}=w_{L}^{C}-e-\delta\left(I_{L}^{N S}-I_{U}\right) \\
r I_{L}^{S}=w_{L}^{C}-(\delta+m)\left(I_{L}^{S}-I_{U}\right) \\
r I_{U}=w_{U}^{C}+a^{C}\left(I_{L}-I_{U}\right)
\end{gathered}
$$

where $w_{L}^{C}, w_{U}^{C}$ are the urban wage and the unemployment benefit respectively, $e$ is the effort level, $r$ the discount rate, $\delta, m$ and $a$ denote the job-destruction, monitoring and job-acquisition rates, respectively. Firms set the efficiency wage such that $I_{L}^{N S}=I_{L}^{S}=I_{L}$ and we obtain that $I_{L}-I_{U}=e / m$. This is the surplus of being employed and it is strictly positive. As in Shapiro and Stiglitz (1984), this a pure incentive effect to deter shirking. This surplus only depends on the monitoring technology, since more monitoring implies less shirking, and on the effort level provided by workers.

Equation (2.4) can be written as:

$$
w_{L}^{C}=e+r I_{L}+\delta\left(I_{L}-I_{U}\right)=e+r I_{U}+(\delta+r)\left(I_{L}-I_{U}\right)
$$


Furthermore, using (2.6) and the fact that $I_{L}-I_{U}=e / m$, this can be written as:

$$
w_{L}^{C}=w_{U}^{C}+e+\frac{e}{m}(a+\delta+r)
$$

Finally, at the steady state, flows out of unemployment equal flows into unemployment, i.e.

$$
a^{C}=\frac{\delta L^{C}}{N-L^{C}-L^{R}}
$$

so that the efficiency wage is finally given by:

$$
w_{L}^{C}=w_{U}^{C}+e+\frac{e}{m}\left[\frac{\delta\left(N-L^{R}\right)}{N-L^{C}-L^{R}}+r\right]
$$

We have the standard effects of the efficiency wage (see Shapiro and Stiglitz, 1984). What is new here is the fact that rural employment affects the efficiency wage. Indeed, $L^{R}$ positively affects $w_{L}^{C}$ because more employment in rural areas implies a higher urban job acquisition rate $a^{C}$ (indeed higher $L^{R}$ leads to a decrease in urban unemployment since there are less competition for urban jobs) and thus urban firms have to increase their wages to meet the NonShirking Condition (2.8). In cities, firms decide their employment level by maximizing their profit. We thus have:

$$
w_{L}^{C}=F^{\prime C}\left(L^{C}\right)
$$

In rural areas, we assume that jobs are mainly menial and wages are flexible and equal to marginal product, so that there is no rural unemployment. We thus have:

$$
w_{L}^{R}=F^{\prime R}\left(L^{R}\right)
$$

We assume that the Inada conditions on both production functions hold. Concerning rural-urban migration, as stated above, we assume that a rural worker cannot search from home but must first be unemployed in the city and then search for a job. Thus, the equilibrium migration condition can be written as:

$$
r I_{U}=\int_{0}^{+\infty} w_{L}^{R} e^{-r t}=\frac{w_{L}^{R}}{r}
$$

The left-hand side is the intertemporal utility of moving to the city (remember that a migrant must first be unemployed) while the right-hand side corresponds to the intertemporal utility of staying in rural areas. Using $(2.4)-(2.7), I_{L}^{N S}=$ $I_{L}^{S}=I_{L}$ and (2.10), we can write condition (2.11) as:

$$
w_{U}^{C}+\frac{e}{m} \frac{\delta L^{C}}{N-L^{C}-L^{R}}=\frac{F^{R}\left(L^{R}\right)}{r}
$$

where $L^{C}$ is determined by (2.9). 
Definition 1. A Harris-Todaro equilibrium with efficiency wages is a 5-tuple $\left(w_{L}^{C}, L^{C}, w_{L}^{R}, U^{C}, L^{R}\right)$ such that (2.8), (2.9), (2.10), (2.1) and (2.12) are satisfied.

In this model, given that $w_{U}^{C}, e, m, \delta, N, r$ are exogenous, an equilibrium is calculated as follows. First, from (2.8), one can calculate the urban efficiency wage as a function of $L^{C}$ and $L^{R}$, that is $w_{L}^{C}\left(L^{C}, L^{R}\right)$. Second, by plugging this value $w_{L}^{C}\left(L^{C}, L^{R}\right)$ in (2.9), one obtains a relationship between $L^{C}$ and $L^{R}$, that we write $L_{w}^{C}\left(L^{R}\right)$ and is given by

$$
w_{U}^{C}+e+\frac{e}{m}\left[\frac{\delta\left(N-L^{R}\right)}{N-L^{C}-L^{R}}+r\right]=F^{\prime C}\left(L^{C}\right)
$$

By totally differentiating (2.13) and using the Inada conditions, we easily obtain:

$$
\frac{\partial L_{w}^{C}}{\partial L^{R}}<0, \lim _{L^{R} \rightarrow 0} L_{w}^{C}=L_{0}^{C}, \lim _{L_{w}^{C} \rightarrow 0} L^{R}=N
$$

where $0<L_{w}^{C}\left(L^{R}\right)<L_{0}^{C}<N$ is the unique solution of the following equation

$$
w_{U}^{C}+e+\frac{e}{m}\left[\frac{\delta N}{N-L_{0}^{C}}+r\right]=F^{\prime C}\left(L_{0}^{C}\right)
$$

Third, the equilibrium-migration condition (2.12) gives another relationship between $L^{C}$ and $L^{R}$, that we denote by $L_{h}^{C}\left(L^{R}\right)$ and has the following properties:

$$
\frac{\partial L_{h}^{C}}{\partial L^{R}}<0, \lim _{L^{R} \rightarrow 0} L_{h}^{C}=N, \lim _{L_{h}^{C} \rightarrow 0} L^{R}=L_{0}^{R}=F^{\prime-1}\left(r w_{U}^{C}\right)
$$

where $0<L_{h}^{C}\left(L^{R}\right)<L_{0}^{R}<N$. Figure 1 describes the two curves (2.13) (labor demand equation) and (2.12) (migration equilibrium condition) in the plane $\left(L^{R}, L^{C}\right)$ and it is easy to see that there exists a unique equilibrium that gives a unique value of $L^{C}$ and a unique value of $L^{R}$ that we denote by $\left(L^{R *}, L^{C *}\right)$.

Finally, plugging $L^{R *}$ and $L^{C *}$ in (2.8), (2.10) and (2.1) gives respectively the equilibrium values of $w_{L}^{C *}, w_{L}^{R *}, U^{C *}$.

\section{[Insert Figure 1 here]}

Let us now study the Todaro paradox in this model. Of course, since $L^{C}$ is an endogenous variable, it is difficult to study the impact of $L^{C}$ on $U^{C}$ or $u^{C}$. However, we can study the impact of a reduction of unemployment benefit $w_{U}^{C}$ on urban unemployment since $w_{U}^{C}$ has a direct impact on $L^{C}$. We have the following result: 
Definition 2. In a model where wage $w_{L}^{C}$ and employment $L^{C}$ are endogenous, a Todaro paradox prevails if an increase or decrease in a policy variable leads to an increase in the equilibrium values of both $L^{C}$ and $U^{C}$ (or $u^{C}$ ). If one takes for example the unemployment benefit $w_{U}^{C}$, then a Todaro paradox prevails if by reducing $w_{U}^{C}$, both $L^{C}$ and $U^{C}$ (or $u^{C}$ ) increase, that is $\partial L^{C} / \partial w_{U}^{C}<0$ and $\partial U^{C} / \partial w_{U}^{C}<0$ (or $\partial u^{C} / \partial w_{U}^{C}<0$ ). Differentiating (2.1), this implies that a Todaro paradox exists if and only if

$$
\frac{\partial L^{R *}}{\partial w_{U}^{C}}>-\frac{\partial L^{C *}}{\partial w_{U}^{C}}>0
$$

Using this definition, let us now study the Todaro paradox in this model. As stated above and described by Figure 1, the equilibrium is determined by two equations (2.12) and (2.13). If we differentiate (2.12), we obtain

$$
L^{R}=L^{R}\left(\underset{-}{w_{U}^{C}}, \underset{-}{e}, \underset{+}{m}, \underset{-}{\delta}, \underset{+}{N}, \underset{-}{r}, L_{-}^{C}\right)
$$

Indeed, a higher unemployment benefit, $w_{U}^{C}$, or effort level, $e$, or job-destruction rate, $\delta$, or discount rate, $r$, or a lower monitoring rate, $m$, or total population, $N$, makes the city more attractive because of higher intertemporal utility of being unemployed in the city, $I_{U}$ (remember that $I_{L}-I_{U}=e / m$ ). Thus more workers leave the rural area, which reduces $L^{R}$. When $L^{C}$ increases, the urban job acquisition rate $a^{C}$ increases and again more rural workers migrate to the city, thus reducing $L^{R}$.

If we now differentiate (2.13), we get:

$$
L^{C}=L^{C}\left(\underset{-}{w_{U}^{C}}, \underset{-}{e}, \underset{+}{m}, \underset{-}{\delta}, \underset{+}{N}, \underset{-}{r}, L_{-}^{R}\right)
$$

where

$$
\frac{\partial L^{C}}{\partial L^{R}}=-\frac{\frac{e}{m} \delta L^{C}}{\frac{e}{m} \delta\left(N-L^{R}\right)-\left(N-L^{C}-L^{R}\right)^{2} F^{\prime \prime C}\left(L^{C}\right)}<0
$$

Indeed, a higher $w_{U}^{C}$, or $e$, or $\delta$, or $r$, or a lower $m$, or $N$, shifts upward the Non-Shirking Condition (2.8), so firms have to pay a higher efficiency wage to prevent shirking. This, in turn, reduces employment since, because of higher wage costs, maximizing-profit firms have to reduce the number of employed. For $L^{R}$, the effect is through the job-acquisition rate $a^{C}$. Indeed, a higher rural employment $L^{R}$ increases $a^{C}$, which obliges firms to increase their urban efficiency wages, which in turn reduces urban labor demand $L^{C}$ because firms maximize their profit. We obtain the following result: 
Proposition 1. In an Harris-Todaro model with urban efficiency wages, decreasing unemployment benefit leads to

(i) an increase in urban employment $L^{C}$, i.e. $\partial L^{C *} / \partial w_{U}^{C}<0$;

(ii) an increase in rural employment $L^{R}$, i.e. $\partial L^{C *} / \partial w_{U}^{C}<0$;

(iii) a decrease in urban unemployment (both in level and rate) $U^{C}$ and $u^{C}$, i.e. $\partial U^{C *} / \partial w_{U}^{C}>0$ and $\partial u^{C *} / \partial w_{U}^{C}>0$.

As a result, there is no Todaro paradox.

The proof of this proposition is tedious and can be found at the end of this appendix. There is thus no Todaro paradox in this model. The intuition is as follows. When the government decreases the unemployment benefit, this has a direct negative effect on urban wages and thus more urban jobs are created. This is the attraction force to the city. But there are two repulsion forces. As before, this implies that rural wages increase but since there are more jobs in cities and efficiency wages act as a worker's discipline device, urban firms reduce their wages because it becomes more difficult to find a job. Because the repulsion forces are strong enough, the net effect is that creating urban jobs via a reduction in unemployment benefit reduces urban unemployment because of the discouraging effect of efficiency wages on migration.

These results are quite interesting. Let us see what happens in the autarky case, i.e. the case of no mobility between rural and urban areas. Indeed, imagine now that migration was totally controlled and that workers, especially rural workers could not migrate to cities. In that case, the two regions ( $C$ and $R$ ) would be totally independent and we would have

$$
\begin{gathered}
U^{C}=N^{C}-L^{C} \\
L^{R}=N^{R}
\end{gathered}
$$

so that the unemployment rate would be given by

$$
u^{C}=\frac{U^{C}}{U^{C}+L^{C}}=\frac{N^{C}-L^{C}}{N^{C}}
$$

Here, only $L^{C}$ is endogenous and not $L^{R}$. Thus, the job acquisition rate and the urban efficiency wage would be given by:

$$
a^{C}=\frac{\delta L^{C}}{N-L^{C}}
$$




$$
w_{L}^{C}=w_{U}^{C}+e+\frac{e}{m}\left[\frac{\delta N^{C}}{N-L^{C}}+r\right]
$$

and the labor demand would still be given by (2.9). The urban labor equilibrium would then be defined as:

$$
w_{U}^{C}+e+\frac{e}{m}\left[\frac{\delta N^{C}}{N-L^{C}}+r\right]=F^{\prime}\left(L^{C}\right)
$$

Definition 3. An efficiency wage equilibrium with no mobility is a triple $\left(w_{L}^{C *}, L^{C *}, w_{L}^{R *}\right)$ such that (2.18) (2.9) and (2.10) are satisfied.

From this definition and by totally differentiating (2.19), we obtain the following result:

Proposition 2. In efficiency wage equilibrium with no mobility, decreasing the unemployment benefit $w_{U}$ always increases urban employment and decreases urban unemployment (both in level and rate), that is

$$
\frac{\partial L^{C}}{\partial w_{U}^{C}}<0, \frac{\partial U^{C}}{\partial w_{U}^{C}}>0, \frac{\partial u^{C}}{\partial w_{U}^{C}}>0
$$

This result is not surprising since when $w_{U}^{C}$ decreases, firms can reduce their efficiency wages and thus hire more workers. There is no effect on rural workers. However, even when rural-urban migration is authorized, we obtain the same results because the repulsion forces are sufficiently strong to thwart the attraction force of a reduction of the unemployment benefit.

\section{Urban search-matching}

We would like to endogeneize both urban wages and urban unemployment using a standard search matching model as in Mortensen and Pissarides (1999) and Pissarides (2000). The starting point is the following matching function

$$
d\left(U^{C}, V^{C}\right)
$$

where $U^{C}$ and $V^{C}$ are the total number of urban unemployed and urban vacancies, respectively. This matching function captures the frictions that search behaviors of both firms and workers imply. It is assumed that $d($.$) is increas-$ ing in its arguments, concave and homogeneous of degree 1 . Thus, the rate at which vacancies are filled is $d\left(U^{C}, V^{C}\right) / V^{C}=d\left(1 / \theta^{C}, 1\right) \equiv q\left(\theta^{C}\right)$, where

$$
\theta^{C}=\frac{V^{C}}{U^{C}}
$$


is a measure of labor market tightness in cities and $q\left(\theta^{C}\right)$ is a Poisson intensity. Similarly, the rate at which an unemployed worker leaves unemployment (job acquisition rate) is now given by

$$
a^{C}=\frac{d\left(U^{C}, V^{C}\right)}{U^{C}} \equiv \theta^{C} q\left(\theta^{C}\right)
$$

In steady-state, the Bellman equations for the employed and unemployed are respectively given by: ${ }^{3}$

$$
\begin{gathered}
r I_{L}=w_{L}^{C}-\delta\left(I_{L}-I_{U}\right) \\
r I_{U}=w_{U}^{C}+\theta^{C} q\left(\theta^{C}\right)\left(I_{L}-I_{U}\right)
\end{gathered}
$$

By combining (3.3) and (3.4), we obtain:

$$
I_{L}-I_{U}=\frac{w_{L}^{C}-w_{U}^{C}}{r+\delta+\theta^{C} q\left(\theta^{C}\right)}
$$

For firms with filled and vacant jobs, we have the following Bellman equations:

$$
\begin{gathered}
r I_{F}=y^{C}-w_{L}^{C}-\delta\left(I_{F}-I_{V}\right) \\
r I_{V}=-\gamma+q\left(\theta^{C}\right)\left(I_{F}-I_{V}\right)
\end{gathered}
$$

where $\gamma$ is the search cost for the firm and $y^{C}$ is the product of the match. Because of free entry, $I_{V}=0$. From (3.7) and using $I_{V}=0$, the value of a job is now equal to:

$$
I_{F}=\frac{\gamma}{q(\theta)}
$$

Firms enter the labor market until the expected benefit $I_{F}$ is equal the expected cost $\gamma / q(\theta)$ (remember that, in a Poisson process, the inverse of the exist rate $q(\theta)$ expresses the average duration of a vacant job). Finally, plugging (3.8) into (3.6) and using $I_{V}=0$, we obtain the following decreasing relation between labor market tightness and wages in equilibrium:

$$
\frac{\gamma}{q\left(\theta^{C}\right)}=\frac{y^{C}-w_{L}^{C}}{r+\delta}
$$

In words, the value of a job is equal to the expected search cost, i.e. the cost per unit of time multiplied by the average duration of search for the firm. So, firms' job creation is endogenous and is determined by (3.9).

Let us now determined the wage. At each period, the total intertemporal surplus is shared through a generalized Nash-bargaining process between the

\footnotetext{
${ }^{3}$ For simplicity, it is assumed that each firm only hires one worker.
} 
firm and the worker. The total surplus is the sum of the surplus of the workers, $I_{L}-I_{U}$, and the surplus of the firms $I_{F}-I_{V}$. At each period, the wage is determined by:

$$
w_{L}^{C}=\arg \max _{w_{L}^{C}}\left(I_{L}-I_{U}\right)^{\beta}\left(I_{F}-I_{V}\right)^{1-\beta}
$$

where $0 \leq \beta \leq 1$ is the bargaining power of workers. First order condition gives:

$$
\frac{\beta}{1-\beta}\left(\frac{\partial I_{L}}{\partial w_{L}^{C}}-\frac{\partial I_{U}}{\partial w_{L}^{C}}\right) I_{F}+\left(I_{L}-I_{u}\right) \frac{\partial I_{F}}{\partial w_{L}^{C}}=0
$$

Since the wage is negotiated at each period, $I_{U}$ does not depend on the current wage $w_{L}^{C}$ and so $\frac{\partial I_{U}}{\partial w_{L}^{C}}=0$. Since by $(3.3), \frac{\partial I_{L}}{\partial w_{L}^{C}}=1 /(r+\delta)$, by $(3.8), I_{F}=\gamma / q(\theta)$ and by (3.6), $\frac{\partial I_{F}}{\partial w_{L}^{C}}=-1 /(r+\delta)$, equation (3.11) can be written as:

$$
I_{L}-I_{U}=\frac{\beta}{1-\beta} \frac{\gamma}{q\left(\theta^{C}\right)}
$$

Then, using (3.5) and (3.9), we finally obtain the following wage:

$$
w_{L}^{C}=(1-\beta) w_{U}^{C}+\beta\left(y^{C}+\gamma \theta^{C}\right)
$$

This is the wage-setting curve (a relation between wages and the state of the labor market, here $\theta^{C}$ ) that replaces, in search-matching models, the traditional labor-supply curve.

As before, the unemployment level in cities in equal to:

$$
U^{C}=N-L^{C}-L^{R}
$$

In steady-state, flows in and out unemployment have to be equal and we obtain the following relationship in cities:

$$
L^{C}=\frac{\theta^{C} q\left(\theta^{C}\right)}{\delta+\theta^{C} q\left(\theta^{C}\right)}\left(N-L^{R}\right)
$$

In rural areas, as before there is no unemployment and the following condition holds:

$$
w_{L}^{R}=F^{\prime R}\left(L^{R}\right)
$$

Finally, we assume that a rural worker cannot search from home but must first be unemployed in the city and then search for a job. Thus the equilibrium migration condition can be written as:

$$
r I_{U}=\frac{w_{L}^{R}}{r}
$$


Using (3.3), (3.4) and (3.5), this can be written as:

$$
\frac{(r+\delta) w_{U}^{C}+\theta^{C} q\left(\theta^{C}\right) w_{L}^{C}}{r+\delta+\theta^{C} q\left(\theta^{C}\right)}=\frac{F^{R}\left(L^{R}\right)}{r}
$$

Definition 4. A Harris-Todaro equilibrium with urban search externalities and bargained wages is a 5-tuple $\left(w_{L}^{C}, \theta^{C}, w_{L}^{R}, L^{C}, U^{C}, V^{C}, L^{R}\right)$ such that (3.13), (3.9), (3.16), (3.15), (3.14), (3.1) and (3.17) are satisfied.

Here is the way the equilibrium is calculated. The system is recursive. First, by combining (3.13) and (3.9), we obtain a unique $\theta^{C *}$ that is only function of parameters and given by:

$$
(1-\beta)\left(y^{C}-w_{U}^{C}\right)-\beta \gamma \theta^{C}=\frac{\gamma(r+\delta)}{q\left(\theta^{C}\right)}
$$

Second, by combining (3.13) and (3.17), we obtain:

$$
\frac{(r+\delta) w_{U}^{C}+\theta^{C} q\left(\theta^{C}\right)\left[(1-\beta) w_{U}^{C}+\beta\left(y^{C}+\gamma \theta^{C}\right)\right]}{r+\delta+\theta^{C} q\left(\theta^{C}\right)}=\frac{F^{R}\left(L^{R}\right)}{r}
$$

which using $\theta^{C *}$ gives a unique $L^{R *}$ as a function of parameters only. Furthermore, by plugging $\theta^{C *}$ and $L^{R *}$ in (3.13), we obtain a unique $L^{C *}$. Figure 2 illustrates the way the equilibrium is calculated.

\section{[Insert Figure 2 here]}

Finally, by plugging $L^{C *}$ and $L^{R *}$ in (3.16) and (3.14), we obtain respectively $w_{L}^{R *}$ and $U^{C *}$ and by plugging $\theta^{C *}$ in (3.18), we obtain $w_{L}^{C *}$. Also, using the values of $\theta^{C *}$ and $U^{C *}$ in (3.1), we obtain the equilibrium number of vacancies in cities, $V^{C *}$.

Here the migration process is more complex. If the government reduces the unemployment benefit, this will again have a direct effect by increasing urban jobs. Indeed, since the wage is reduced (see (3.13)), more firms enter the market (see (3.9)) and thus more urban jobs are created. There will still be a repulsion force because of the positive effect on rural wage. But since workers face less search frictions (more firms enter the market) more rural workers will migrate to the cities, which in turn increases workers' search frictions. We have the following result: ${ }^{4}$

\footnotetext{
${ }^{4}$ The proof of Proposition 3 can be found at the end of this appendix.
} 
Proposition 3. In an Harris-Todaro model with urban search externalities and bargained wages, decreasing unemployment benefit $w_{U}^{C}$ leads to:

(i) an increase in both urban job creation $\theta^{C}$ and urban employment $L^{C}$,

(ii) an ambiguous effect on both rural employment $L^{R}$ and urban unemployment (both in level and rate) $U^{C}$ and $u^{C}$.

Furthermore, if the following condition holds,

$$
w_{L}^{C}-w_{L}^{R} / r+\frac{\beta \gamma}{\frac{\partial\left[\theta^{C} q\left(\theta^{C}\right)\right]}{\partial \theta^{C}}}<-F^{\prime \prime R}\left(L^{R}\right)\left(N-L^{R}\right) \frac{\delta\left[r+\delta+\theta^{C} q\left(\theta^{C}\right)\right]}{r\left[\delta+\theta^{C} q\left(\theta^{C}\right)\right]^{2}}
$$

then a Todaro paradox prevails, that is decreasing $w_{U}^{C}$ increases both urban employment and unemployment.

A decrease in $w_{U}^{C}$ has a direct negative effect on bargained wages. As a result, because it is cheaper and thus more profitable to hire a worker, more firms enter the urban labor market and more jobs are created; consequently $\theta^{C}$ and $L^{C}$ increase. However, the effect on rural-urban migration and thus on $L^{R}$ is more subtle. Indeed, when $w_{U}^{C}$ decreases, there is a direct negative effect on migration since urban wages are lower and thus less rural workers migrate (thus $L^{R}$ increases). There is also an indirect positive effect on migration since a lower $w_{U}^{C}$ increases $w_{L}^{C}$ and thus more firms enter the urban labor market (if the search cost $c$ is not too large) and more jobs are created. This increases rural-urban migration and thus reduces $L^{R}$. The net effect is thus ambiguous. The same ambiguity arises when one studies the effect of $w_{U}^{C}$ on urban unemployment. These results mean that there is a possibility for a Todaro paradox, that is a decrease in unemployment benefit can increase both urban employment and unemployment. This is true if at least the indirect positive effect on migration is larger than direct negative effect mentioned above.

As in the efficiency wage model, let us study the case with no mobility between the two regions. The wage $w_{L}^{C}$ and the job creation rate $\theta^{C}$ are still be given by (3.13) and (3.18) respectively but $L^{C}$ is now equal to:

$$
L^{C}=\frac{\theta^{C} q\left(\theta^{C}\right)}{\delta+\theta^{C} q\left(\theta^{C}\right)} N^{C}
$$

Definition 5. A search equilibrium with no mobility is a triple $\left(w_{L}^{C *}, \theta^{C *}, L^{C *}, w_{L}^{R *}\right)$ such that (3.13), (3.18), (3.20) and (2.10) are satisfied. 
By totally differentiating (3.18), (3.20) and (3.14), we have the following result:

Proposition 4. In a search equilibrium with no mobility, decreasing the unemployment benefit $w_{U}^{C}$ increases both urban job creation $\theta^{C}$ and urban employment $L^{C}$ and decreases urban unemployment (both in level and rate), that is:

$$
\frac{\partial \theta^{C}}{\partial w_{U}^{C}}<0, \frac{\partial L^{C}}{\partial w_{U}^{C}}<0, \frac{\partial U^{C}}{\partial w_{U}^{C}}>0, \frac{\partial u^{C}}{\partial w_{U}^{C}}>0
$$

Again this is very intuitive. If the unemployment benefit decreases, wages are reduced (see (3.13)) because workers have lower outside option. As a result, firms' expected profit increases and thus more jobs are created, which increases $\theta^{C}$. This raises urban employment $L^{C}$ (see (3.20)) and decreases both the level and the rate of urban unemployment since $U^{C}=N-L^{C}$ and $u^{C}=\delta /\left(\delta+\theta^{C} q\left(\theta^{C}\right)\right)$.

\section{Concluding remarks}

In this paper, we have reexamined the Todaro paradox in the context of both efficiency wage and search-matching models. The definition a Todaro paradox adopted here is a little bit different than that of the standard literature. Indeed, in the present paper where both wages and employment in cities are endogenous, a Todaro paradox exists if an increase or decrease in an exogenous policy variable leads to an increase in the equilibrium values of both urban employment and unemployment. In the present paper, we have chosen to focus on urban unemployment benefit, which in the context of a third world country could be interpreted as family or institutional support in the urban sector. In the efficiency wage model, we find that there is no Todaro paradox while this is not always true in a search-matching model since a decrease in the urban unemployment benefit can increase both urban employment and unemployment. Indeed, even though in both models an unemployment benefit policy has a direct impact on the decision to migrate since it directly affects $I_{U}$, the lifetime expected utility of moving to the city, the effects on the urban labor market are different. This is because in a search matching model it is time consuming to obtain a job and to fill a vacancy in the urban area and the creation of jobs is endogenous. As a result, a policy that reduces the urban unemployment benefit has a direct impact on the rate at which people and firms live their state of non-activity. In an efficiency wage model where there 
is no search frictions and no endogenous job creation, the same policy has only an indirect effect on the exit rate of the unemployed and the vacant firms via the efficiency wage.

We believe that this paper gives some answers to important questions about migration in developing countries. Indeed, any policy implemented in cities should take into account the induced effect on mobility and migration from rural areas or cities of smaller size (even if it is illegal). It would also be interesting to consider other urban policies such as subsidizing urban wages or facilitating the entry of urban firms in the labor market. We leave these projects for future research.

\section{Proof of Propositions}

\subsection{Proof of Proposition 1}

The Harris-Todaro equilibrium is defined by equations (2.13) and (2.12). From (2.13), we obtain a $L^{C}\left(L^{R}, w_{U}^{C}\right)$, whose properties are given by (2.16). Plugging this value in (2.12), we obtain the following equation:

$$
w_{U}^{C}+\frac{e}{m} \frac{\delta L^{C}\left(L^{R *}, h_{U}\right)}{N-L^{C}\left(L^{R *}, h_{U}\right)-L^{R *}}=\frac{F^{\prime R}\left(L^{R *}\right)}{r}
$$

that gives a unique $L^{R}$, which is a function of exogenous parameters only, and in particular a function of $w_{U}^{C}$. This is why we denote the equilibrium value that we obtain by $L^{R *} \equiv L^{R}\left(w_{U}^{C}\right)$. By totally differentiating this equation, we obtain:

$\frac{\partial L^{R *}}{\partial w_{U}^{C}}=-\frac{\left[N-L^{C}\left(L^{R *}, w_{U}^{C}\right)-L^{R *}\right]^{2}+\frac{e \delta}{m} \frac{\partial L^{C}\left(L^{R *}, w_{U}^{C}\right)}{\partial w_{U}^{C}}\left(N-L^{R *}\right)}{\frac{e \delta}{m}\left[\frac{\partial L^{C}}{\partial L^{R *}}\left(N-L^{R *}\right)+L^{C}\left(L^{R *}, w_{U}^{C}\right)\right]-\left[N-L^{C}\left(L^{R *}, w_{U}^{C}\right)-L^{R *}\right]^{2} \frac{F^{\prime \prime R}\left(L^{R *}\right)}{r}}$

where, using (2.16), we have $\frac{\partial L^{C}\left(L^{R *}, w_{U}^{C}\right)}{\partial w_{U}^{C}}<0$ and $\frac{\partial L^{C}\left(L_{U}^{R *}, w_{U}^{C}\right)}{\partial L^{R *}}<0$, so we cannot sign this derivative.

Now, plugging this value $L^{R *} \equiv L^{R}\left(w_{U}^{C}\right)$ in (2.13), we obtain a unique $L^{C *} \equiv L^{C}\left(w_{U}^{C}\right)$, which is only function of parameters and given implicitly by the following equation:

$$
w_{U}^{C}+e+\frac{e}{m}\left[\frac{\delta\left(N-L^{R *}\right)}{N-L^{C *}-L^{R *}}+r\right]=F^{\prime C}\left(L^{C *}\right)
$$

where $L^{C *} \equiv L^{C}\left(L^{R *}, w_{U}^{C}\right)$. Again, by totally differentiating this equation, we 
obtain:

$$
\frac{\partial L^{C *}}{\partial w_{U}^{C}}=-\frac{\left(N-L^{C *}-L^{R *}\right)^{2}+\frac{e}{m} \delta \frac{\partial L^{R *}}{\partial w_{U}^{C}} L^{C *}}{\frac{e}{m} \delta\left(N-L^{R *}\right)-\left(N-L^{C *}-L^{R *}\right)^{2} F^{\prime \prime C}\left(L^{C *}\right)}
$$

where $\frac{\partial L^{R *}}{\partial w_{U}^{C}}$ is given by $(5.1)$.

Let us now calculate the exact value of $\frac{\partial L^{R *}}{\partial w_{U}^{C}}$. By plugging (2.17) and (5.2) in (5.1) and solving in $\frac{\partial L^{R *}}{\partial w_{U}^{C}}$, we obtain:

$$
\frac{\partial L^{R *}}{\partial w_{U}^{C}}=\frac{\left(N-L^{C}-L^{R *}\right)^{4} F^{\prime \prime C}\left(L^{C *}\right)}{\left(\frac{e \delta}{m}\right)^{2} L^{C}\left(N-L^{R *}\right)-\left(N-L^{C *}-L^{R *}\right)^{2} B}<0
$$

where

$B \equiv \frac{e}{m} \delta L^{C} F^{\prime \prime C}\left(L^{C}\right)+\frac{F^{\prime \prime R}\left(L^{R *}\right)}{r}\left[\frac{e}{m} \delta L^{C}\left(N-L^{R *}\right)-\left(N-L^{C *}-L^{R *}\right)^{2} F^{\prime \prime C}\left(L^{C *}\right)\right]<0$

We can now calculate $\frac{\partial L^{C *}}{\partial w_{U}^{C}}$. By plugging (5.3) in (5.2), we obtain:

$$
\begin{aligned}
& \frac{\partial L^{C *}}{\partial w_{U}^{C}}=-\frac{\left(N-L^{C *}-L^{R *}\right)^{2}+\frac{e}{m} \delta \frac{\partial L^{R *}}{\partial w_{U}^{C}} L^{C *}}{\frac{e}{m} \delta\left(N-L^{R *}\right)-\left(N-L^{C *}-L^{R *}\right)^{2} F^{\prime \prime C}\left(L^{C *}\right)} \\
= & \frac{\left(N-L^{C *}-L^{R *}\right)^{2}-\frac{\left(N-L^{C *}-L^{R *}\right)^{4} F^{\prime \prime C}\left(L^{C *}\right)}{\left(N-L^{C}-L^{R}\right)^{2} B-\left(\frac{e}{m} \delta\right)^{2} L^{C *}\left(N-L^{R *}\right)} \frac{e}{m} \delta L^{C *}}{\frac{e}{m} \delta\left(N-L^{R *}\right)-\left(N-L^{C *}-L^{R *}\right)^{2} F^{\prime \prime C}\left(L^{C *}\right)} \\
& {\left[\left(N-L^{C}-L^{R}\right)^{2} B-\left(\frac{e}{m} \delta\right)^{2} L^{C *}\left(N-L^{R *}\right)\right]\left(N-L^{C *}-L^{R *}\right)^{2} } \\
< & \left(N-L^{C *}-L^{R *}\right)^{4} F^{\prime \prime C}\left(L^{C *}\right) \frac{e}{m} \delta L^{C *}
\end{aligned}
$$

Let us show that $\frac{\partial L^{C *}}{\partial w_{U}^{C}}<0$. Since the denominator is positive, we have

$$
\begin{gathered}
\frac{\partial L^{C *}}{\partial w_{U}^{C}}<0 \\
\Leftrightarrow\left(N-L^{C *}-L^{R *}\right)^{2}>\frac{\left(N-L^{C *}-L^{R *}\right)^{4} F^{\prime \prime C}\left(L^{C *}\right)}{\left(N-L^{C}-L^{R}\right)^{2} B-\left(\frac{e}{m} \delta\right)^{2} L^{C *}\left(N-L^{R *}\right)} \frac{e}{m} \delta L^{C *} \\
\Leftrightarrow\left(N-L^{C *}-L^{R *}\right)^{2}\left[B-F^{\prime \prime C}\left(L^{C *}\right) \frac{e}{m} \delta L^{C *}\right]-\left(\frac{e}{m} \delta\right)^{2} L^{C *}\left(N-L^{R *}\right)<0
\end{gathered}
$$

Since

$$
\begin{aligned}
& B-F^{\prime \prime C}\left(L^{C *}\right) \frac{e}{m} \delta L^{C *} \\
= & \frac{F^{\prime \prime R}\left(L^{R *}\right)}{r}\left[\frac{e}{m} \delta\left(N-L^{R *}\right)-\left(N-L^{C *}-L^{R *}\right)^{2} F^{\prime \prime C}\left(L^{C *}\right)\right]<0
\end{aligned}
$$


This implies that

$$
\left(N-L^{C}-L^{R}\right)^{2}\left[B-F^{\prime \prime C}\left(L^{C *}\right) \frac{e}{m} \delta L^{C *}\right]-\left(\frac{e}{m} \delta\right)^{2} L^{C *}\left(N-L^{R *}\right)<0
$$

is always true. Thus

$$
\frac{\partial L^{C *}}{\partial w_{U}^{C}}<0
$$

Let us now calculate $\frac{\partial U^{C *}}{\partial w_{U}^{C}}$. By differentiating (2.1), we have:

$$
\frac{\partial U^{C *}}{\partial w_{U}^{C}}=-\frac{\partial L^{C *}}{\partial w_{U}^{C}}-\frac{\partial L^{R *}}{\partial w_{U}^{C}}>0
$$

Moreover, since the unemployment rate is defined as

$$
u^{C *}=\frac{U^{C *}}{U^{C *}+L^{C *}}
$$

then

$$
\frac{\partial u^{C *}}{\partial w_{U}^{C}}=\frac{\frac{\partial U^{C *}}{\partial w_{U}^{C}} L^{C *}-U^{C *} \frac{\partial L^{C *}}{\partial w_{U}^{C}}}{\left(U^{C *}+L^{C *}\right)^{2}}>0
$$

Finally, using Definition 2 and in particular (2.14), it is easy to verify that there is no Todaro paradox.

\subsection{Proof of Proposition 3}

By totally differentiating (3.18), it is easy to verify that

$$
\frac{\partial \theta^{C}}{\partial w_{U}^{C}}=\frac{1-\beta}{-\beta \gamma+q^{\prime}\left(\theta^{C}\right) \gamma(r+\delta) /\left[q\left(\theta^{C}\right)\right]^{2}}<0
$$

By totally differentiating (3.19), we obtain:

$$
\begin{gathered}
\frac{\partial L^{R}}{\partial \theta^{C}}=\frac{\frac{\partial\left[\theta^{C} q\left(\theta^{C}\right)\right]}{\partial \theta^{C}} w_{L}^{C}+\theta^{C} q\left(\theta^{C}\right)\left[\gamma-w_{L}^{R} / r\right]}{\left[r+\delta+\theta^{C} q\left(\theta^{C}\right)\right] F^{\prime \prime R}\left(L^{R}\right) / r} \\
\frac{\partial L^{R}}{\partial w_{U}^{C}}=\frac{r+\delta+\theta^{C} q\left(\theta^{C}\right)(1-\beta)+\frac{\partial \theta^{C}}{\partial w_{U}^{C}}\left[\frac{\partial\left[\theta^{C} q\left(\theta^{C}\right)\right]}{\partial \theta^{C}}\left(w_{L}^{C}-w_{L}^{R} / r\right)+\beta \gamma\right]}{\left[r+\delta+\theta^{C} q\left(\theta^{C}\right)\right] F^{\prime \prime R}\left(L^{R}\right) / r}
\end{gathered}
$$

A sufficient condition for $\frac{\partial L^{R}}{\partial \theta^{C}}<0$ is $\gamma>w_{L}^{R} / r$. We also have:

$$
\frac{\partial L^{R}}{\partial w_{U}^{C}}=\frac{d L^{R}}{d w_{U}^{C}}+\frac{\partial L^{R}}{\partial \theta^{C}} \frac{\partial \theta^{C}}{\partial w_{U}^{C}}
$$


with

$$
\frac{d L^{R}}{d w_{U}^{C}}=\frac{r+\delta+\theta^{C} q\left(\theta^{C}\right)(1-\beta)}{\left[r+\delta+\theta^{C} q\left(\theta^{C}\right)\right] F^{\prime \prime R}\left(L^{R}\right) / r}<0
$$

By totally differentiating (3.13), we obtain:

$$
\begin{gathered}
\frac{\partial L^{C *}}{\partial \theta^{C}}=\left(N-L^{R}\right) \frac{\partial\left[\theta^{C} q\left(\theta^{C}\right)\right]}{\partial \theta^{C}} \frac{\delta}{\left[\delta+\theta^{C} q\left(\theta^{C}\right)\right]^{2}}>0 \\
\frac{\partial L^{C *}}{\partial L^{R}}=-\frac{\theta^{C} q\left(\theta^{C}\right)}{\delta+\theta^{C} q\left(\theta^{C}\right)}<0 \\
\frac{\partial L^{C *}}{\partial w_{U}^{C}}=\frac{\partial L^{C *}}{\partial \theta^{C}} \frac{\partial \theta^{C}}{\partial w_{U}^{C}}<0
\end{gathered}
$$

Thus, since $U^{C}=N-L^{C}-L^{R}$, we have

$$
\frac{\partial U^{C *}}{\partial w_{U}^{C}}=-\left(\frac{\partial L^{C *}}{\partial w_{U}^{C}}+\frac{\partial L^{R}}{\partial w_{U}^{C}}\right)
$$

Finally, a Todaro paradox exists if

$$
\frac{\partial L^{R *}}{\partial w_{U}^{C}}>-\frac{\partial L^{C *}}{\partial w_{U}^{C}}
$$

which using (5.6), (5.7) and (5.5) is equivalent to

$$
\begin{aligned}
& r+\delta+\theta^{C} q\left(\theta^{C}\right)(1-\beta) \\
> & -\frac{\partial \theta^{C}}{\partial w_{U}^{C}}\left[\frac{\partial\left[\theta^{C} q\left(\theta^{C}\right)\right]}{\partial \theta^{C}}\left[w_{L}^{C}-w_{L}^{R} / r+\left(N-L^{R}\right) \frac{\delta\left[r+\delta+\theta^{C} q\left(\theta^{C}\right)\right]}{\left[\delta+\theta^{C} q\left(\theta^{C}\right)\right]^{2}} F^{\prime \prime R}\left(L^{R}\right) / r\right]+\beta \gamma\right]
\end{aligned}
$$

Thus if

$\frac{\partial\left[\theta^{C} q\left(\theta^{C}\right)\right]}{\partial \theta^{C}}\left[w_{L}^{C}-w_{L}^{R} / r+\left(N-L^{R}\right) \frac{\delta\left[r+\delta+\theta^{C} q\left(\theta^{C}\right)\right]}{\left[\delta+\theta^{C} q\left(\theta^{C}\right)\right]^{2}} F^{\prime \prime R}\left(L^{R}\right) / r\right]+\beta \gamma<0$

a Todaro paradox always exists. This is equivalent to:

$$
-\left(N-L^{R}\right) \frac{\delta\left[r+\delta+\theta^{C} q\left(\theta^{C}\right)\right]}{\left[\delta+\theta^{C} q\left(\theta^{C}\right)\right]^{2}} F^{\prime \prime R}\left(L^{R}\right) / r>\left(w_{L}^{C}-w_{L}^{R} / r\right)+\frac{\beta \gamma}{\frac{\partial\left[\theta^{C} q\left(\theta^{C}\right)\right]}{\partial \theta^{C}}}
$$

which is the condition displayed in the proposition. 


\section{References}

[1] Arellano, J-P. (1981), "Do more jobs in the modern sector increase urban unemployment?" Journal of Development Economics, 8, 241-247.

[2] Banerjee, B. (1984), "Information flow, expectations and job search : Rural-to-urban migration process in India," Journal of Development Economics, 15, 239-257.

[3] Blomqvist, A. (1978), "Urban job creation and unemployment in LDCs. Todaro vs Harris and Todaro," Journal of Development Economics, 5, $3-18$.

[4] Brueckner, J.K. (1990), "Analyzing third world urbanization: A model with empirical evidence," Economic Development and Cultural Change, $38,587-610$.

[5] Brueckner, J.K. and H-A. Kim (2001), "Land markets in the HarrisTodaro model: A new factor equilibrating rural-urban migration," Journal of Regional Science, 41, 507-520.

[6] Brueckner, J.K. and Y. Zenou (1999), "Harris-Todaro models with a land market," Regional Science and Urban Economics, 29, 317-339.

[7] Coulson, E., Laing, D. and P. Wang (2001), "Spatial mismatch in search equilibrium," Journal of Labor Economics, 19, 949-972.

[8] Devine, T. and N. Kiefer (1991), Empirical Labor Economics: The Search Approach, Oxford: Oxford University Press.

[9] Dickens, W.T. and L.F. Katz (1987), "Inter-industry wage differences and industry characteristics," In: K. Lang and J.S. Leonard (Eds.), Unemployment and the Structure of Labor Markets, New York: Basil Blackwell, pp. 48-89.

[10] Fields, G.S. (1975), "Rural-urban migration, urban unemployment and underemployment, and job-search activity in LDCs," Journal of Development Economics, 2, 165-187.

[11] Fields, G.S. (1989), "On-the-job search in a labor market model. Ex ante Choices and ex post outcomes," Journal of Development Economics, 30, 159-178. 
[12] Harris, J.R. and M.P. Todaro (1970), "Migration, unemployment and development: A two-sector analysis," American Economic Review, 60, 126-142.

[13] Knight, J. and L. Song (2005), Towards a Labour Market in China, Oxford: Oxford University Press.

[14] Kruger, A. and L. Summers (1988), "Efficiency wages and the interindustry wage structure," Econometrica, 56, 259-293.

[15] Laing, D., Park, C. and P. Wang (2005), "A modified Harris-Todaro model of rural-urban migration for China," In: F. Kwan and E. Yu (Eds.), Critical Issues in China's Growth and Development, London: Ashgate, pp. 245-264.

[16] Moene, K. (1988), "A reformulation of the Harris-Todaro mechanism with endogenous wages," Economics Letters, 27, 387-390.

[17] Mohtadi, H. (1989), "Migration and job search in a dualistic economy. A Todaro-Stigler synthesis," Economics Letters, 29, 373-378.

[18] Mortensen, D.T. and C.A. Pissarides (1999), "New developments in models of search in the labor market," In: D. Card and O. Ashenfelter (Eds.), Handbook of Labor Economics, Amsterdam: Elsevier Science, pp. 25672627.

[19] Murphy, K.M. and R.H. Topel (1990), "Efficiency wage reconsidered: Theory and evidence. In: Y. Weiss and G. Fishelson (Eds.), Advances in the Theory and Measurement of Unemployment, New York: St. Martin's Press, pp. 104-240.

[20] Nagakome, M. (1989), "Urban unemployment and the spatial structure of labor markets: an examination of the Todaro paradox in a spatial context," Journal of Regional Science, 29, 161-170.

[21] Neal, D. (1993), "Supervision and wages across industries," Review of Economics and Statistics, 75, 409-417.

[22] Ortega J. (2000), "Pareto-improving immigration in an economy with equilibrium unemployment," Economic Journal, 110, 92-112. 
[23] Petrongolo, B. and C.A. Pissarides (2001), "Looking into the black box: A survey of the matching function," Journal of Economic Literature, 39, 390-431.

[24] Pissarides, C.A. (2000), Equilibrium Unemployment Theory, Second edition, M.I.T. Press, Cambridge.

[25] Raimondos, P. (1993), "On the Todaro paradox," Economics Letters, 42, 261-267.

[26] Sato, Y. (2004), "Migration, frictional unemployment, and welfareimproving labor policies," Journal of Regional Science, 44, 773-793.

[27] Shapiro, C. and J.E. Stiglitz (1984), "Equilibrium unemployment as a worker discipline device," American Economic Review, 74, 433-444.

[28] Stark, O., Gupta, M. and D. Levahri (1991), "Equilibrium urban unemployment in developing countries. Is migration the culprit?" Economics Letters, 37, 477-482.

[29] Stiglitz, J.E. (1974), "Alternative theories of wage determination and unemployment in LDCs: The labor turnover model," Quarterly Journal of Economics, 88, 194-227.

[30] Stiglitz, J.E. (1976), "The efficiency wage hypothesis, surplus labor, and the distribution of income in LDCs," Oxford Economic Papers, 28, 185207.

[31] Takagi, Y. (1984), "The migation function and the Todaro paradox" Regional Science and Urban Economics, 14, 219-230.

[32] Todaro, M.P. (1969), "A model of labor migration and urban unemployment in less developed countries," American Economic Review, 59, 138148.

[33] Todaro, M.P. (1976), "Urban job creation, induced migration and rising unemployment: A formulation and simplified empirical test for LDCs," Journal of Development Economics, 3, 211-226.

[34] Zarembka, P. (1970), "Labor migration and urban unemployment. Comment," American Economic Review, 60, 184-186. 
[35] Zenou, Y. and T.E. Smith (1995), "Efficiency wages, involuntary unemployment and urban spatial structure", Regional Science and Urban Economics, 25, 821-845. 
Figure 1: Harris-Todaro equilibrium with efficiency wages

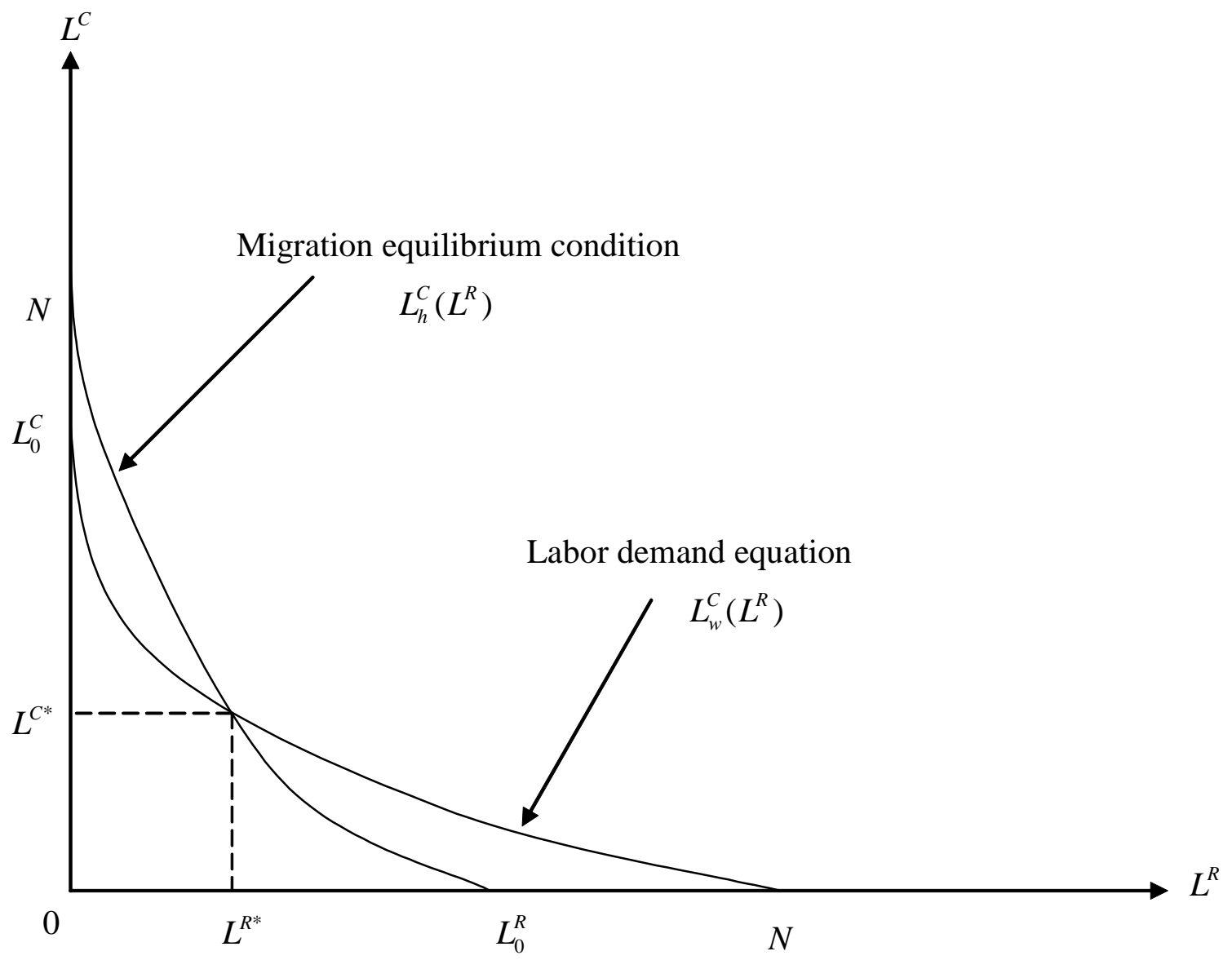


Figure 2: Harris-Todaro equilibrium with search externalities

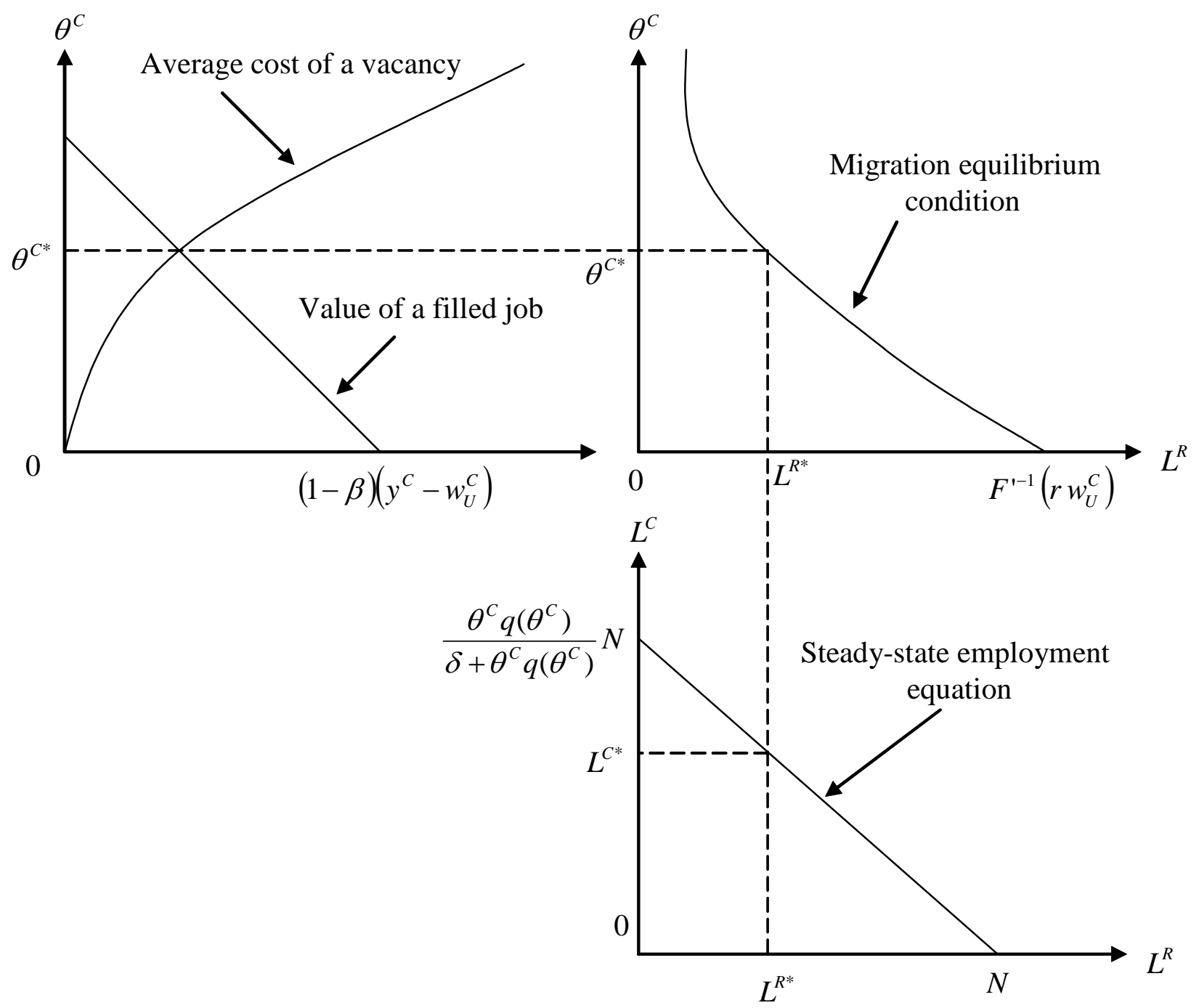

